\title{
Comparative phylogeography of four Indo-Pacific moray eel species (Muraenidae) reveals comparable ocean-wide genetic connectivity despite five-fold differences in available adult habitat
}

\author{
Joshua S. Reece ${ }^{1,4, *}$, Brian W. Bowen ${ }^{2}$, David G. Smith ${ }^{3}$, Allan Larson ${ }^{1}$ \\ ${ }^{1}$ Washington University in St. Louis, Department of Biology, Campus Box 1137, One Brookings Drive, St. Louis, \\ Missouri 63130, USA \\ ${ }^{2}$ Hawaii Institute of Marine Biology, PO Box 1346, Kaneohe, Hawaii 96744, USA \\ ${ }^{3}$ Smithsonian Institution, Museum Support Center MRC 534, 4210 Silver Hill Road, Suitland, Maryland 20746, USA \\ ${ }^{4}$ Present address: University of California at Santa Cruz, 100 Schaffer Road, Santa Cruz, California 95062, USA
}

\begin{abstract}
Most coral reef fishes have non-migratory adults and depend on a pelagic larval stage for dispersal. Species with long pelagic larval duration (PLD) can have tremendous dispersal potential and thus display little geographic-genetic differentiation among reef habitats. Restricted adult niche breadth due to habitat specialization can have the opposite effect of fragmenting populations and increasing geographic-genetic differentiation. If long PLD suffices to ensure widespread gene flow among reef populations, we predict similar geographic-genetic homogeneity within species whose adults differ in niche breadth. We tested this hypothesis using a comparative phylogeographic study of 4 sympatric moray eel species that differ in the amount of available habitat within their reported ranges. We generated molecular genetic data for Echidna nebulosa $(\mathrm{N}=79)$ and Gymnomuraena zebra $(\mathrm{N}=67)$ to measure geographic-genetic structure within these species, whose adult habitat is very restricted for moray eels, and compared these results to identical measurements previously published for habitat generalists Gymnothorax undulatus and Gymnothorax flavimarginatus. These 4 species share an ocean-wide distribution with adults occupying the same reefs; however, adults of E. nebulosa and G. zebra are restricted to shallow waters and occupy only $20 \%$ of the area occupied by the Gymnothorax species. Mitochondrial (632 bp of cytochrome $b$ and $596 \mathrm{bp}$ of cytochrome oxidase I) genomic sequences revealed high genetic variation ( $h=0.995$ to 0.998 ) and low geographic-genetic differentiation (pairwise $\Phi_{\mathrm{ST}}<0.07$ and not significant) for each species across $22000 \mathrm{~km}$ of the Indo-Pacific. Nuclear genomic sequences (420 bp of RAG-1 and $746 \mathrm{bp}$ of RAG-2) demonstrated 16 to 25 haplotypes per marker within each species with minimal geographic-genetic differentiation among populations. This suggests that in cosmopolitan and highly dispersive species such as morays, larval life history can ensure widespread gene flow despite a 5 -fold difference in the habitat breadth occupied by adult populations.
\end{abstract}

KEY WORDS: Gene flow $\cdot$ Phylogeography $\cdot$ Connectivity $\cdot$ Reef fish $\cdot$ Leptocephalus $\cdot$ Moray eel

\section{INTRODUCTION}

Many marine organisms disperse exclusively through a pelagic larval stage (Thresher 1984) and the pelagic larval duration (PLD) influences the dis- persal ability of these species (Waples 1987, Doherty et al. 1995, Bohonak 1999). Weersing \& Toonen (2009) demonstrated that species with very long PLD maintain greater geographic-genetic homogeneity among populations than do species having very short 
PLDs. Adult niche breadth can also influence the genetic differentiation among locations within species (Blanchet et al. 2010). It is unclear whether high dispersal ability in reef fishes erases effects of adult habitat fragmentation on geographic-genetic structuring within species. We are unaware of any prior study that directly tests the hypothesis that high pelagic larval dispersal overcomes differences in adult niche breadth to ensure comparable genetic homogeneity among populations in codistributed species of reef fishes.

We used 4 species of moray eel to examine the effect of adult niche breadth on species with high PLD. These species provide a phylogenetically controlled study system of species with similar life histories, a sedentary adult stage, and 2 species each with broad and narrow niche preferences as adults. All 4 species have the thin transparent leptocephalus larvae characteristic of the superorder Elopomorpha, and overlapping geographic ranges that span the entire tropical Indo-Pacific.

Adults of Gymnothorax undulatus and Gymnothorax flavimarginatus are habitat generalists that occupy reefs and rocky substrates from depths of 1 to $150 \mathrm{~m}$, and feeding generalists that consume fishes, cephalopods and crustaceans (HarmelinVivien 1979, Yukihira et al. 1994). Echidna nebulosa and Gymnomuraena zebra are habitat specialists relative to other morays; they occupy only the shallow portions of the Gymnothorax species' range, between 0 and $15 \mathrm{~m}$ (but usually $<2 \mathrm{~m}$ ). They are specialist feeders on crustaceans, a small subset of the Gymnothorax diet (Hiatt \& Strasburg 1960, Yukihira et al. 1994). Detailed habitat data are not available for these or many other coral reef fishes; however, the depth of reef habitat used by a species (Sampayo et al. 2007, Chatfield et al. 2010) and diet (Gaughan \& Potter 1997, Scharf et al. 2000, Mehta 2009) are major dimensions by which adult niche breadth varies among coral reef fishes. For both measures, the 2 generalist Gymnothorax species have similar niche breadth, and the specialists $E$. nebulosa and G. zebra occupy a subset of the Gymnothorax niches. Adults of all 4 species are highly philopatric to a small portion of reef habitat; they spawn near that habitat (Moyer \& Zaiser 1982, Ferraris 1985) and dispersal occurs entirely through leptocephali. The leptocephali of many species are widely distributed in the ocean and are thought to promote high levels of dispersal through long PLDs and possibly their swimming abilities (Smith 1989, McCleave \& Miller 1994, Kuroki et al. 2006, Miller et al. 2006, Miller 2009).
Because Gymnomuraena zebra and Echidna nebulosa are restricted to the shallower portions of the Gymnothorax range, their habitat is more fragmented. Habitat fragmentation can induce genetic differentiation by decreasing gene flow in marine fishes (Deza \& Anderson 2010), whereas more continuously distributed habitat promotes geographic and genetic continuity among populations. If high PLD suffices to produce high gene flow among populations, we should observe similar levels of geographic-genetic continuity within species that have similar PLDs but differ dramatically in adult niche breadth and habitat fragmentation.

Gymnothorax undulatus and $G$. flavimarginatus both maintain high gene flow throughout their distributions (Reece et al. 2010a). Here, we present comparative phylogeographic analyses using orthologous mitochondrial and nuclear genomic markers for 2 habitat specialists Echidna nebulosa and Gymnomuraena zebra. We estimate the distributions of each species using geographic information systems and then compare genetic diversity, population coalescence times, and geographic-genetic structure among the 4 species to test the hypothesis that niche breadth/habitat specialization can influence phylogeographic structure despite long PLDs.

\section{MATERIALS AND METHODS}

Estimating niche breadth using habitat depth. We used records for museum specimens, field guides, and extensive field sampling to estimate habitat utilization by depth for each species (see Table S1 in the supplement at www.int-res.com/articles/suppl/ m437p269_supp.pdf). We examined depth information for 214 individuals of Gymnothorax flavimarginatus, 166 individuals of G. undulatus, 77 individuals of Gymnomuraena zebra, and 163 individuals of Echidna nebulosa. The online resource FishBase (www.fishbase.org) and our own collections provided specimen locality and depth data. Museum specimens of moray eels are biased toward small individuals collected in shallow waters by rotenone and dip nets. Maximum depths are thus a much better indication of the depth range of a species. We recorded mean and maximum depths from FishBase and confirmed depths directly from specimen tags in the Smithsonian (National Museum of Natural History, Washington, DC) ichthyology collection. We used the depths occupied by a species to generate areas of suitable habitat by depth as a quantitative measure of niche (habitat) breadth using ArcGIS v.9 and 
bathymetric data (database ETOPO1) from the National Oceanic and Atmospheric Association (NOAA) National Geophysical Data Center (www.ngdc.noaa.gov). ETOPO1 data were imported into ArcGIS and rasterized (this translates pixels of an image into a grid of depth information). We binned topographic data into 3 elevation classes: -1 to $-15 \mathrm{~m},-15$ to $-150 \mathrm{~m}$, and -1 to $-150 \mathrm{~m}$. Range data for each species from FishBase include locality data from multiple collections. Within the polygon encompassing the sympatric ranges of all 4 species, we computed the area in $\mathrm{m}^{2}$ for each depth class. All areas between -1 and $-15 \mathrm{~m}$ altitude were included for Echidna nebulosa and Gymnomuraena zebra. All areas between -1 and $-150 \mathrm{~m}$ were calculated for the 2 Gymnothorax species. We express the portion of habitat used by the habitat specialists as a percentage of the total habitat used by the generalist Gymnothorax species. Although exact dimensions of adult subpopulations and relative areas occupied undoubtedly changed with global climatic cycles (Reece et al. 2010a), we assume that the generalist Gymnothorax species consistently occupied larger portions of the reefs than did the specialists E. nebulosa and $G$. zebra.

We assume that PLD does not differ substantially among the 4 species. Morays have among the longest PLDs of coral reef fishes, and reef species with PLDs longer than $45 \mathrm{~d}$ almost universally have ocean-wide distributions (Brothers \& Thresher 1985, Klanten et al. 2007, Horne et al. 2008, Gaither et al. 2010, Reece et al. 2010a). Our inferences apply only to coral reef fishes that disperse strictly through a pelagic larval phase, and not to species with both long PLDs and migratory adults. PLDs are estimated from otoliths, which contain ringed increments deposited daily in most larval fishes. These rings indicate PLD when counted at time of recruitment to adult habitat, just prior to metamorphosis (see Kuroki et al. 2006). An estimate of PLD for Echidna nebulosa of $80 \mathrm{~d}$ (Brothers \& Thresher 1985) is from a juvenile adult. We examined otoliths from 2 juvenile individuals of each species obtained from the pet trade to make similar estimates. We followed Kuroki et al. (2006) and identified between 60 and 80 distinct rings prior to metamorphosis for both specimens for all 4 species. Prior estimates for morays indicate minimum values of 40 to 80 d (Brothers \& Thresher 1985, Smith 1989, Bishop et al. 2000), and even longer PLDs among other anguilliform leptocephali (see review in Miller 2009). Moray larvae occur at high abundance in offshore currents, indicating long PLDs (Leis \& Miller 1976, Miller et al. 2006, Miller \& McCleave 2007). We assume that, while difficult to estimate precisely, the PLDs of the 4 species in question are well beyond the 15 to $30 \mathrm{~d}$ average for most reef fishes (Lester \& Ruttenberg 2005).

Population genetic analyses. We obtained tissues through spear fishing, baited lobster traps, museum collections, local fishermen, and the pet trade when reliable records were available for DNA analysis of Echidna nebulosa $(\mathrm{N}=79)$ and Gymnomuraena zebra $(\mathrm{N}=67)$. Depth data was recorded for all sampled specimens, which were included in the analysis of depth range as described above. Each specimen was identified to a sampling location in one of 11 geographic localities distributed across 3 biogeographic regions: the Indian Ocean, western/central Pacific, and eastern Pacific Ocean. The Sunda Shelf separates the Indian Ocean from the western/central Pacific, and the Eastern Pacific Barrier separates the western/ central Pacific from the eastern Pacific (Fig. 1).

In the present study, DNA isolation and sequence generation for Echidna nebulosa and Gymnomuraena zebra followed previously published methods used for Gymnothorax undulatus and G. flavimarginatus to provide comparable measurements of population genetic structure (Reece et al. 2010a). We sampled portions of 2 mitochondrial and 2 nuclear (RAG-1 and RAG-2) markers and tested these genetic data for geographic-genetic structure following the methods of Reece et al. (2010a), including reconstruction of haplotype networks in the program TCS v.1.2.1 (Clement et al. 2000), estimates of haplotype and nucleotide diversity in DNAsp v.5.0 (Rozas et al. 2003), pairwise $\Phi_{\mathrm{ST}}$ and an Analysis of Molecular Variance (AMOVA) completed in Arlequin v.3.1.1 (Excoffier \& Schneider 2005). For AMOVAs, we compared individuals grouped by geographic locality and biogeographic region with all locations combined. Pairwise $\Phi_{\mathrm{ST}}$ comparisons included all localities with more than 5 specimens for mtDNA, RAG-1, and $R A G-2$, with a B-H (Benjamini \& Hochberg 1995) correction for multiple comparisons. We tested for large-scale patterns of isolation by distance using Mantel tests to compare a matrix of pairwise $\Phi_{\mathrm{ST}}$ values with a matrix of linear geographic distances between sites in the program Passage v.2.0 (Rosenberg \& Anderson 2011).

To ensure comparability of phylogeographic structure among species, we estimated demographic processes and coalescence times for the observed genetic variation. We inferred the history of demographic expansion/contraction using Fu's $F_{\mathrm{S}}$ (Fu 1997) and mismatch distributions of mtDNA. We used 2 metrics to test for the fit of observed data to a 
unimodal mismatch distribution that represents a sudden expansion model (Rogers 1995): (1) Harpending's Raggedness Index (Harpending 1994), which examines the maximum number of observed differences between haplotypes under an expectation of an expanding population, and (2) the sum of squared deviations (Rogers \& Harpending 1992), a parametric bootstrap approach that computes confidence intervals around an expected unimodal distribution and tests to see if observed mismatched distributions fall within or outside those confidence intervals at $\alpha=$ 0.05 (Schneider \& Excoffier 1999).

We estimated coalescence times for genetic variation within Echidna nebulosa and Gymnomuraena zebra separately in the program BEAST v.1.5.4 (Drummond \& Rambaut 2007). Estimates of coalescence times for the 2 Gymnothorax species, based on mutation rates estimated for all 4 markers analyzed in this study, had been calculated using the same methods in the previous study (Reece et al. 2010a).

\section{RESULTS}

\section{Depth range and dispersal capabilities}

Depths recorded for species used in this study are presented in Table S1 in the supplement (www.intres.com/articles/suppl/m437p269_supp.pdf). Gymnothorax flavimarginatus is captured consistently between 1 and $150 \mathrm{~m}$ below sea level (Myers 1991), and the average depth for specimens examined and captured for this study was $22 \mathrm{~m}$, with a maximum depth of $150 \mathrm{~m}(\mathrm{~N}=214)$. Gymnothorax undulatus is also consistently observed between 1 and $150 \mathrm{~m}$ depth (Mundy 2005, Randall 2007), and we observed mean and maximum depths of 24 and $150 \mathrm{~m}$ depth, respectively $(\mathrm{N}=166)$. Gymnomuraena zebra is typically observed between 0 and $15 \mathrm{~m}$ (Sommer et al. 1996, Mundy 2005), and the average of depth records examined for this study was $1.9 \mathrm{~m}$, with a maximum of $15 \mathrm{~m}(\mathrm{~N}=77)$. The reported depth range for Echidna nebulosa is also between 1 and $15 \mathrm{~m}$ (Kuiter

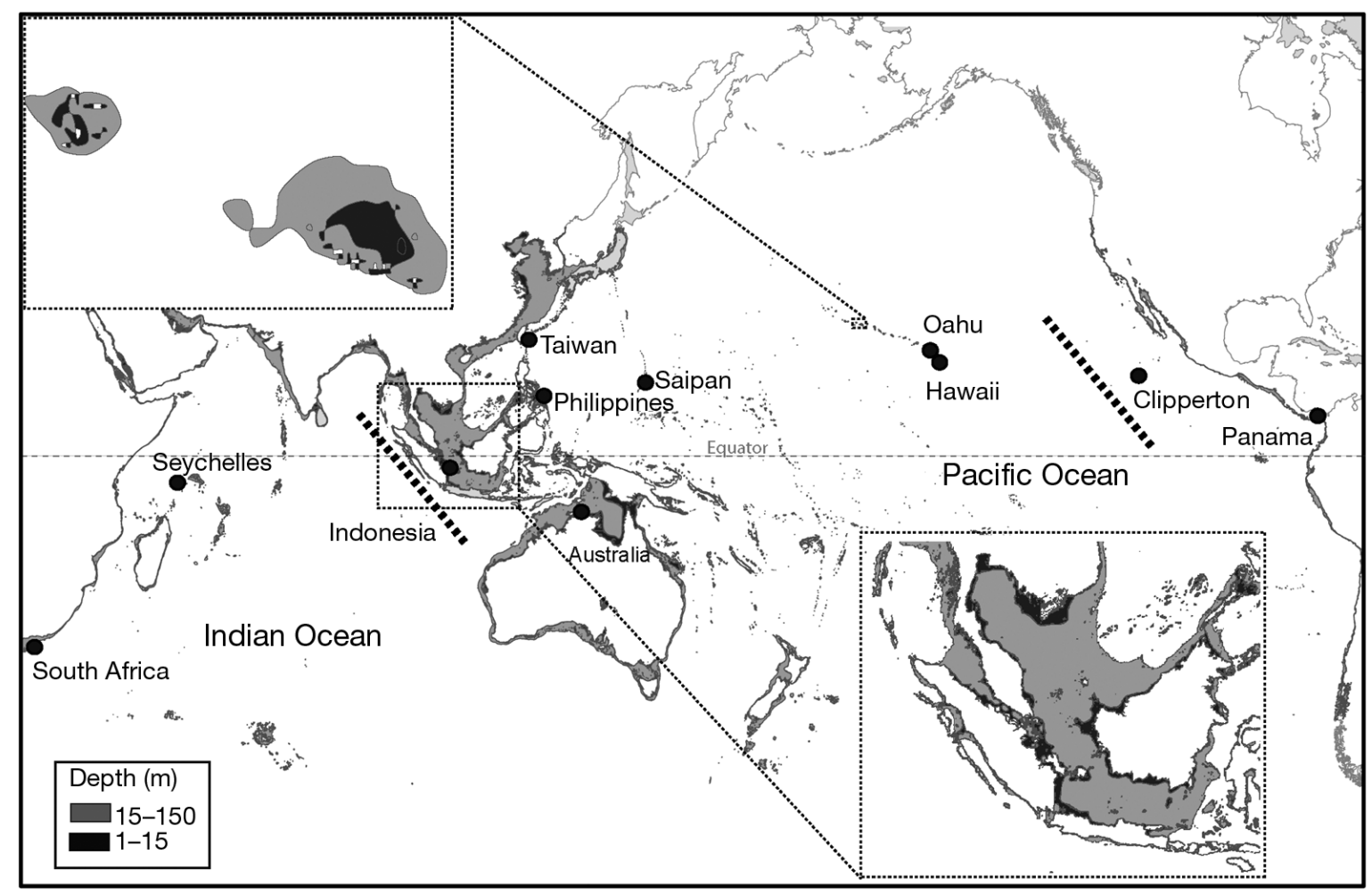

Fig. 1. Map of sampling localities and potential habitat by depth. Habitat depths are given in grey (15 to $150 \mathrm{~m})$ and black (1 to $15 \mathrm{~m}$ ) in the geographic range reported for the 4 species (see 'Materials and methods'). The 2 broad-niche species Gymnothorax undulatus and G. flavimarginatus potentially occupy all areas shaded in grey and black, whereas the 2 narrow-niche species Echidna nebulosa and Gymnomuraena zebra are restricted to black-shaded areas. The top left inset shows the seamount habitat at Maro reef in the northwestern Hawaiian Islands (sampled in Reece et al. 2010a); the center of the seamount is shallow habitat in black, surrounded by deeper habitat in grey. The lower right inset shows a continental shelf habitat in a portion of the Coral Triangle; land is white and bordered by shallow coastal habitat in black, with deeper offshore habitat in grey. Thick dotted lines represent major biogeographic barriers, the Sunda Shelf to the west and the Eastern Pacific Barrier to the east 
Fig. 2. Mitochondrial DNA haplotype networks for Echidna nebulosa, Gymnomuraena zebra, Gymnothorax flavimarginatus, and Gymnothorax undulatus. Squares represent observed haplotypes inferred to be ancestral to all other observed haplotypes; circles denote additional observed haplotypes, and small black-filled circles denote unsampled haplotypes inferred to connect observed haplotypes. The size of the circle or square is proportional to the number of individuals sampled for networks within each species; sizes of entire networks between species have been scaled for presentation. Pie-chart shading denotes the 3 oceanic regions delimited by the Sunda Shelf and Eastern Pacific Barrier (Fig. 1): Indian Ocean (black), west/central Pacific (white), and eastern Pacific Ocean (grey)

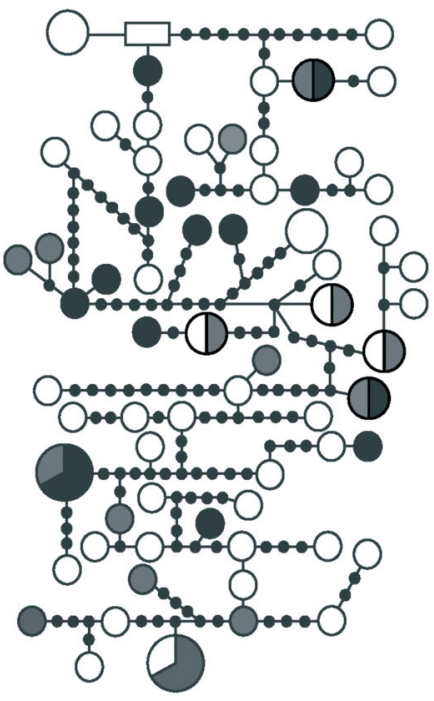

Echidna nebulosa

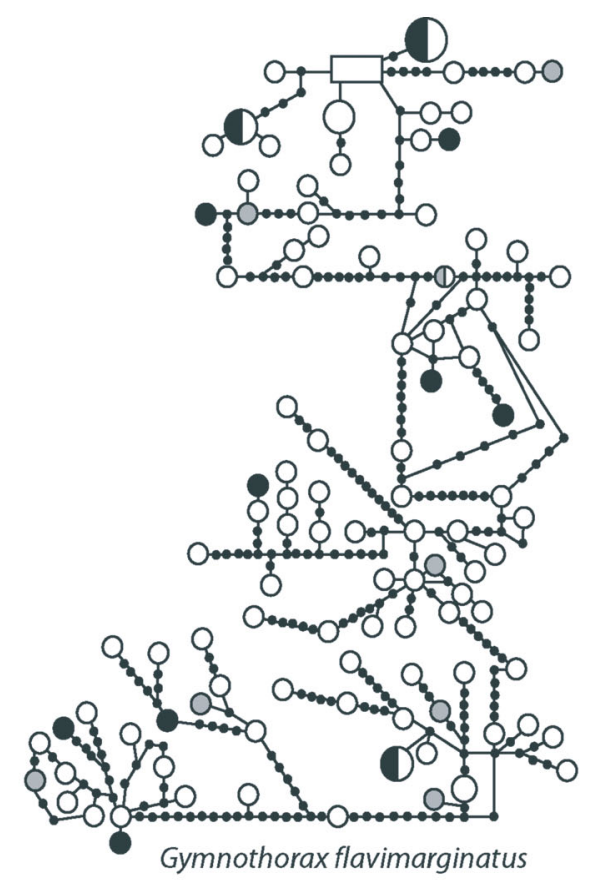

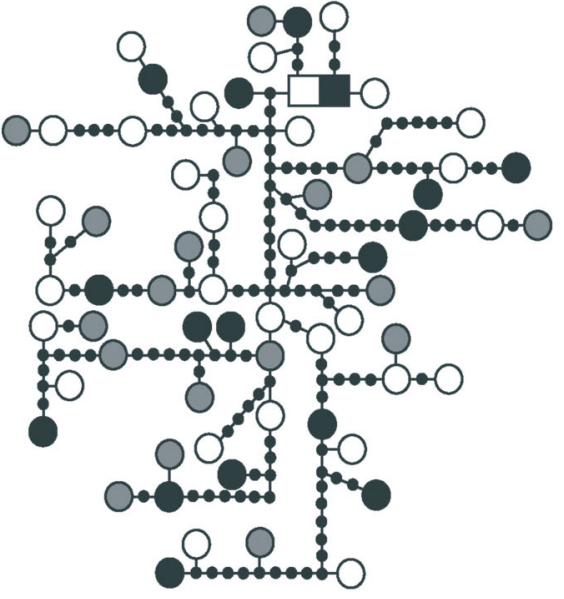

Gymnomuraena zebra

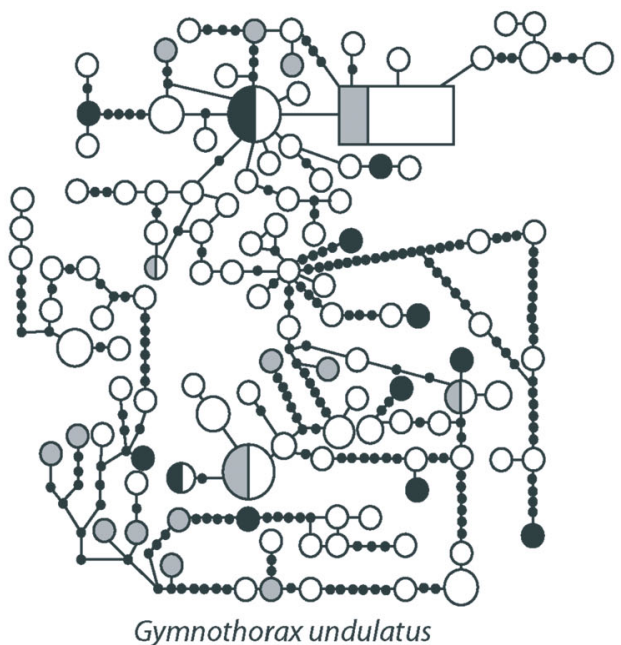

DNA sequence data
1998, Mundy 2005), and the average depth record was $1.8 \mathrm{~m}$ with a maximum of $15 \mathrm{~m}(\mathrm{~N}=163)$. There is an account of G. zebra at $40 \mathrm{~m}$ (e.g. Randall 2007); however, this species primarily inhabits shallow waters. We report maximum depth approximations because means reflect collectors' biases more than distributions of individuals.

Within the range of all 4 species, ArcGIS analyses of the bathymetric landscape estimated $650000 \mathrm{~m}^{2}$ of suitable habitat by depth between -1 and $-15 \mathrm{~m}$, and $3.25 \times 10^{6} \mathrm{~m}^{2}$ of habitat between -1 and $-150 \mathrm{~m}$ (Fig. 1). Therefore Echidna nebulosa and Gymnomuraena zebra occupy approximately $20 \%$ of the habitat available to the Gymnothorax species. Given the tendency of both specialists to inhabit areas of $<2 \mathrm{~m}$ depth, this is probably an overestimate.
For Echidna nebulosa and Gymnomuraena zebra, we present new DNA sequences for portions of 2 mitochondrial (632 bp of cytochrome $b$ and $596 \mathrm{bp}$ of

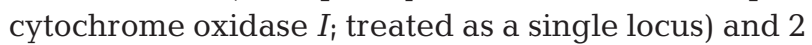
nuclear (420 bp of RAG-1 and $746 \mathrm{bp}$ of $R A G-2$ ) markers for a total of $2394 \mathrm{bp}$ of DNA. GenBank accession numbers for unique sequences generated in this study are JN008945-JN009084 for E. nebulosa and JN020361-JN020488 for G. zebra. These data were compared with the previously obtained data for the 2 Gymnothorax species (Reece et al. 2010a). Haplotype networks of all 4 species (Figs. $2 \& 3$ ) show that genetic relatedness among haplotypes lacks geographic pattern; closely related haplotypes were 


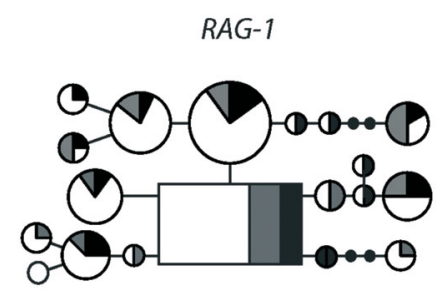

RAG-2

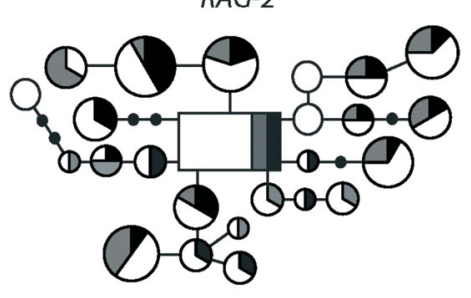

Echidna nebulosa

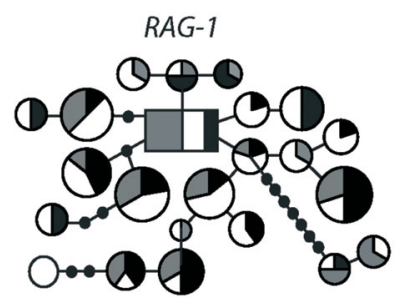

RAG-2

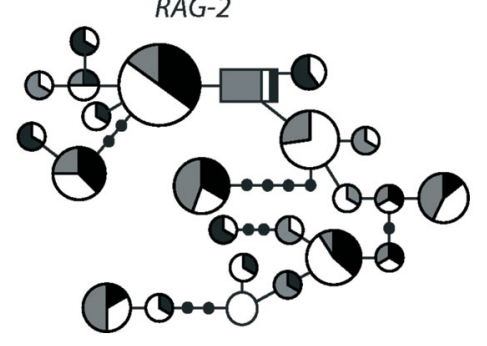

Gymnomuraena zebra
Fig. 3. Nuclear RAG-1 and RAG-2 haplotype networks for Echidna nebulosa and Gymnomuraena zebra. Squares represent inferred ancestral haplotypes; circles are additional haplotypes, and small blackfilled circles are missing haplotypes. The size of the circle or square is proportional to the number of individuals sampled for networks within each species. Pie-chart shading denotes the 3 oceanic regions delimited by the Sunda Shelf and Eastern Pacific Barrier (Fig. 1): Indian Ocean (black), west/ central Pacific (white), and eastern Pacific Ocean (grey) observed in disparate geographic regions, indicating low geographic-genetic structure. Table 1 shows the numbers of alleles for each marker and each species, and mtDNA haplotype and nucleotide diversity.

Echidna nebulosa and Gymnomuraena zebra show evidence of species-wide population growth similar to the 2 Gymnothorax species (Table 1), in the form of significantly negative Fu's $F_{\mathrm{S}}$ and mismatched distributions. Estimates of coalescence times for E. nebulosa and G. zebra from BEAST indicate that geographic patterns of genetic diversity in both species evolved within the last 2.2 to 9.1 million years (Myr) (95\% $\mathrm{PPD}$; i.e. the $95 \%$ posterior probability distribution, equivalent to a $95 \%$ confidence interval surrounding the most probable estimate) and broadly overlap with those reported for the 2 Gymnothorax species
(Table 1); this confirms the temporal and demographic comparability of geographic-genetic structure across all 4 species. Pairwise $\Phi_{\mathrm{ST}}$ comparisons across locations of mtDNA and both nuclear loci for all 4 species showed no significant differentiation, indicating high gene flow throughout the species' ranges (mtDNA results for E. nebulosa and G. zebra are presented in Table 2). The AMOVA results demonstrate that $>95 \%$ of genetic variation in each of the 4 species occurs within populations, indicating little to no geographic population structure. The amount of total genetic variation explained by oceanic regions delimited by the Sunda Shelf and Eastern Pacific Barrier $\left(\Phi_{\mathrm{CT}}\right)$ is 0.3 and $0.1 \%$ of the variation for $G$. zebra and $E$. nebulosa, respectively, not significantly different from zero and nearly identical to results from the $2 \mathrm{Gym}$ -

Table 1. Results of tests of genetic data from 4 species of moray eel showing the number of individuals sampled, the number of alleles (mtDNA, RAG-1, RAG-2), mtDNA haplotype $(h)$ and nucleotide $(\pi)$ diversity, coalescence time for standing variation (TMRCA: time to most recent common ancestry) based on all 3 gene regions, portion of genetic variance among biogeographic regions $\left(\Phi_{\mathrm{CT}}\right)$ based on mtDNA, and evidence of demographic expansion in the form of Fu's $F_{\mathrm{S}}$ for mtDNA (significant $\Phi_{\mathrm{CT}}$ and $F_{\mathrm{S}}$ values in bold). The mismatch distributions' p-values are the result of the sum of squared deviations tests and demonstrate (all p-values > 0.05) that observed mismatched distributions fall within the $95 \%$ confidence intervals of data generated under a model of population growth. The values for the Harpending's Raggedness Index (HRI) are given, and are all non-significant at $\alpha=0.05$, also indicating that observed data conform to a model of population growth. Mitochondrial DNA was the only marker variable enough to be informative for AMOVA, Fu's $F_{\mathrm{S}}$ and mismatch distributions, but RAG-1 and RAG-2 showed no significant structure. A significant negative $F_{\mathrm{S}}$ indicates that the null hypothesis of constant population size is rejected in favor of demographic expansion, while non-significant p-values from mismatch distributions are consistent with a null hypothesis of demographic expansion. Data for Gymnothorax undulatus and G. flavimarginatus are from Reece et al. (2010a)

\begin{tabular}{|lccccccccc|}
\hline Species & $\mathrm{N}$ & No. alleles & $h$ & $\pi$ & $\begin{array}{c}\text { TMRCA } \\
(\mathrm{Myr})\end{array}$ & $\Phi_{\mathrm{CT}}$ & $F_{\mathrm{S}}$ & \multicolumn{2}{c|}{$\begin{array}{c}\text { Mismatch distributions } \\
\text { HRI }\end{array}$} \\
\hline Gymnothorax undulatus & 165 & $112,23,22$ & 0.997 & 0.012 & $3.5-8.6$ & $\mathbf{0 . 0 3 9}$ & $\mathbf{- 2 4}$ & 0.42 & 0.20 \\
Gymnothorax flavimarginatus & 124 & $104,16,18$ & 0.997 & 0.012 & $1.7-3.0$ & 0.009 & $\mathbf{- 2 4}$ & 0.78 & 0.10 \\
Gymnomuraena zebra & 67 & $64,23,24$ & 0.998 & 0.012 & $2.2-5.3$ & 0.003 & $\mathbf{- 5 7}$ & 0.77 & 0.002 \\
Echidna nebulosa & 79 & $67,19,25$ & 0.995 & 0.014 & $4.2-9.1$ & 0.001 & $\mathbf{- 4 5}$ & 0.68 & 0.002 \\
\hline
\end{tabular}


Table 2. Pairwise $\Phi_{\mathrm{ST}}$ values across geographical localities for Gymnomuraena zebra (below diagonal) and Echidna nebulosa (above diagonal) for mtDNA. No comparison was significant with or without the Benjamini-Hochberg (B-H) correction for multiple comparisons, indicating no population structure. No pairwise comparison was significant in either of the nuclear markers for either species (data not shown). Negative values have no biological interpretation and are statistically indistinguishable from zero. Blank spaces correspond to localities not shared between the 2 species. The 2 columns on the right represent sample sizes by locality for E. nebulosa (Ene, n= 79) and G. zebra (Gze, n =67)

\begin{tabular}{|c|c|c|c|c|c|c|c|c|c|c|c|c|}
\hline & Clipperton & Panama & Hawaii & Oahu & Australia & Saipan & Indonesia & Philippines & Taiwan & S. Africa & Ene & Gze \\
\hline Clipperton & & -0.39 & -0.50 & -0.41 & -0.43 & -0.58 & -0.49 & -0.31 & -0.38 & -0.45 & 1 & 4 \\
\hline Panama & -0.03 & & -0.03 & -0.02 & 0.00 & -0.05 & -0.05 & -0.01 & -0.04 & -0.02 & 15 & 14 \\
\hline Hawaii & 0.01 & -0.06 & & -0.03 & -0.10 & -0.13 & -0.05 & 0.02 & -0.03 & -0.05 & 9 & 10 \\
\hline Oahu & & & & & -0.03 & -0.06 & -0.06 & -0.06 & -0.07 & -0.04 & 6 & 0 \\
\hline Australia & & & & & & -0.16 & -0.01 & 0.04 & 0.00 & -0.06 & 5 & 0 \\
\hline Saipan & & & & & & & -0.10 & -0.01 & -0.06 & -0.09 & 5 & 0 \\
\hline Indonesia & -0.16 & 0.01 & 0.03 & & & & & -0.02 & -0.08 & -0.05 & 7 & 5 \\
\hline Philippines & -0.07 & -0.01 & 0.00 & & & & -0.04 & & 0.01 & -0.01 & 10 & 13 \\
\hline Taiwan & & & & & & & & -0.08 & & -0.07 & 5 & 2 \\
\hline S. Africa & -0.05 & -0.05 & -0.04 & & & & -0.02 & -0.04 & & & 15 & 14 \\
\hline Seychelles & 0.04 & 0.02 & -0.02 & & & & 0.01 & 0.07 & & 0.03 & 0 & 5 \\
\hline
\end{tabular}

nothorax species (Table 1). Tests for isolation by distance revealed no significant association between geographic and genetic distances based on a Mantel test (all $R<0.001$, p-values $>0.3$ ).

Phylogenetic analyses indicate that the 4 species compared in this study have evolved independently for at least $20 \mathrm{Myr}$ (Reece et al. 2010b). Our comparisons of geographic-genetic structuring within these species should be free of any phylogenetic artifacts because the phylogenetic separation among these species greatly exceeds estimates of coalescence times within species.

\section{DISCUSSION}

In Gymnomuraena zebra and Echidna nebulosa, the distribution of genetic diversity and the relationships among haplotypes reveal almost no geographic structure among ocean basins for either the mitochondrial or nuclear markers (Figs. 2 \& 3). Geographic-genetic homogeneity seems even greater for these 2 shallow-water species than for the habitat generalists Gymnothorax undulatus and Gymnothorax flavimarginatus. As summarized by AMOVA, despite high variation at all loci (Table 1) the total proportion of genetic variation that exists as differences among oceanic regions is $<0.4 \%$ for $G$. zebra and E. nebulosa, compared to 4 and $1 \%$ in G. undulatus and G. flavimarginatus, respectively. Minimum coalescence times estimated for genetic variation within E. nebulosa (4.2 Myr) and G. zebra (2.2 Myr) span multiple climatic cycles in which the Sunda Shelf would have emerged as a land barrier separat- ing the Indian Ocean from the Pacific Ocean (Voris 2000), providing ample opportunities for developing geographic structure, yet none was observed. None of the 4 species showed significant associations between genetic and geographic distances (Table 2; see also Table 2 in Reece et al. 2010a) as evaluated by Mantel's tests. Gymnothorax species showed similar demographic estimates of population growth to those for E. nebulosa and G. zebra, nearly identical levels of haplotype and nucleotide diversity, overlapping coalescence times, and only slightly lower levels of connectivity across these barriers despite at least a 5fold difference in adult habitat (Table 1).

Our new data confirm predictions of our prior study that the leptocephalus larva of moray eels permits ocean-wide exchange of genes among populations, because it is very unlikely that adult moray eels could move long distances through the open ocean between regions. The effectiveness of this mechanism is evident in our findings that the greater habitat fragmentation characteristic of Echidna nebulosa and Gymnomuraena zebra adults does not diminish the high levels of gene flow throughout the Indo-Pacific, or the maintenance of high levels of genetic variation for both mitochondrial and nuclear genomes. Our estimated coalescence times indicate that current haplotype variation represents at least several million years of accumulation. If the smaller (and shallower) habitat of the E. nebulosa and G. zebra adult populations had produced greater local extinction and recolonization of populations relative to the Gymnothorax species, E. nebulosa and G. zebra should show lower levels of variation and more recent coalescence times than the Gymnothorax spe- 
cies. In contrast to this prediction, all 4 moray species show nearly identical levels of nuclear haplotypic variation (Table 1). For all species, the number of mitochondrial haplotypes reported closely tracks sample size (Table 1), with no indication that the species differ greatly in mtDNA variation. The wide dispersal of leptocephalus larvae appears to permit moray species to maintain similarly high levels of genetic variation despite a 5-fold difference in the amount of suitable habitat available to adult individuals. This inference assumes that all 4 species with comparable larval durations disperse similarly, and show low and similar levels of intraspecific variation in PLD and associated dispersal capabilities. Some non-moray anguilliforms show regional variation in PLD (Réveillac et al. 2008), but for the purposes of our interpretations we expect that this variation is minimal relative to the very high PLD of these species.

One potential criticism of our sampling strategy is that we might detect greater phylogeographic structure with more geographic and population sampling. We designed our sampling to investigate large-scale patterns across the Indo-Pacific. If local geographic fragmentation occurred in any of the 4 species, then it should be exaggerated at the ocean-wide scale $(22000 \mathrm{~km})$ of their entire distribution. Transient, local geographic isolation likely does occur in all 4 species, but the range-wide pattern that emerges across reconstructions of each species' history is geographic homogenization of genetic structure. It is likely that geographic structure develops over ecological timescales of thousands to tens of thousands of years, and our results do not suggest that larvae disperse across oceanic basins every generation. However, the effective number of migrants between populations averaged across each species' evolutionary history appears to be sufficient to erase geographicgenetic structure over timescales as short as tens to hundreds of thousands of years (Reece et al. 2010a).

Previous studies have shown that PLD correlates with dispersal only in extreme cases of very long or very short PLDs (e.g. Weersing \& Toonen 2009). At intermediate PLDs (15 to $60 \mathrm{~d}$ ), other aspects of life history, ecology, larval behavior, and niche breadth influence dispersal and population genetic structure (Rocha et al. 2002, Gaither et al. 2010). We show in a comparative framework that in broadly distributed species, high PLDs can indeed supersede differences in habitat and ecological specialization and permit ocean-wide genetic homogeneity. Both specialist and generalist moray eels maintain connectivity across the entire Indo-Pacific, the largest tropical habitat on earth.
Acknowledgements. Funding for this project was provided by National Science Foundation grants DDIG-0909756 to A.L. and J.S.R. and OCE-0453167 and OCE-0929031 to B.W.B. Additional funding was provided to J.S.R. through the PADI Foundation, the Society of Systematic Biologists, the Fish Barcode of Life Initiative, the DeepFin Project, and the National Geographic Young Scientists Award. We thank J. Hunt and L. Weigt of the Smithsonian Institution, A. Suzumoto and J. Randall of the Bishop Museum, R. Kosaki and the crew of the NOAA ship Hi'ialakai, the Stock Assessment Program at the NOAA Pacific Islands Fisheries Science Center, and the Hawaii Institute of Marine Biology staff. Tissues were provided by the University of Kansas Biodiversity Institute, the Smithsonian Institution, Australian Museum, the South Africa Institute for Aquatic Biodiversity, and the California Aquarium. Thanks to Allan Connell, R. Toonen, and M. Furtado of Koolau Pets for assistance with specimens. V. Goz and K. Joshi contributed to the genetic data used in this study. G. Bernardi, P. Borsa, M. Craig, J. Eble, K. Krakos, R. Mehta, J. Patterson, L. Rocha, A. Templeton, V. Wagner, and anonymous reviewers provided helpful comments on this manuscript.

\section{LITERATURE CITED}

Benjamini Y, Hochberg Y (1995) Controlling the false discovery rate: a practical and powerful approach to multiple testing. J R Stat Soc B 57:289-300

Bishop RE, Torres JJ, Crabtree RE (2000) Chemical composition and growth indices in leptocephalus larvae. Mar Biol 137:205-214

Blanchet S, Rey O, Etienne R, Lek S, Loot G (2010) Speciesspecific responses to landscape fragmentation: implications for management strategies. Evol Appl 3:291-304

Bohonak AJ (1999) Dispersal, gene flow and population structure. Q Rev Biol 74:21-45

Brothers EB, Thresher RE (1985) Pelagic duration, dispersal, and the distribution of Indo-Pacific coral reef fishes. In: Reaka ML (ed) The ecology of coral reefs. Symposia Series for Undersea Research. NOAA Undersea Research Program, Vol 3, No 1. US Department of Commerce, Washington, DC, p 53-69

> Chatfield BS, Van Niel KP, Kendrick GA, Harvey ES (2010) Combining environmental gradients to explain and predict the structure of demersal fish distributions. J Biogeogr 37:593-605

Clement M, Posada D, Crandall KA (2000) TCS: a computer program to estimate genealogies. Mol Ecol 9:1657-1659

Deza AA, Anderson TW (2010) Habitat fragmentation, patch size, and the recruitment and abundance of kelp forest fishes. Mar Ecol Prog Ser 416:229-240

Doherty PJ, Planes S, Mather P (1995) Gene flow and larval duration in seven species of fish from the Great Barrier Reef. Ecology 76:2373-2391

> Drummond AJ, Rambaut A (2007) BEAST: Bayesian evolutionary analysis by sampling trees. BMC Evol Biol 7:214

Excoffier L, Schneider S (2005) Arlequin (version 3.0): an integrated software package for population genetics data analysis. Evol Bioinform Online 1:47-50

Ferraris CJ Jr (1985) Redescription and spawning behavior of the Muraenid eel Gymnothorax herrei. Copeia 2: $518-520$

Fu YX (1997) Statistical tests of neutrality of mutations against population growth, hitchhiking and background selection. Genetics 147:915-925 
Gaither MR, Toonen RJ, Robertson DR, Planes S, Bowen BW (2010) Genetic evaluation of marine biogeographic barriers: perspectives from two widespread Indo-Pacific snappers (Lutjanus spp.). J Biogeogr 37:133-147

Gaughan DJ, Potter IC (1997) Analysis of diet and feeding strategies within an assemblage of estuarine larval fish and an objective assessment of dietary niche overlap. Fish Bull 95:722-731

Harmelin-Vivien ML (1979) Ichtyofaune des récifs coralliens de Tuléar (Madagascar): écologie et relations trophiques. PhD thesis, Université d'Aix-Marseille, Marseille

Harpending RC (1994) Signature of ancient population growth in a low-resolution mitochondrial DNA mismatch distribution. Hum Biol 66:591-600

Hiatt RW, Strasburg DW (1960) Ecological relationships of the fish fauna on coral reefs of the Marshall Islands. Ecol Monogr 30:65-127

- Horne JB, van Herwerden L, Choat HJ, Robertson DR (2008) High population connectivity across the Indo-Pacific: congruent lack of phylogeographic structure in 3 reef fish congeners. Mol Phylogenet Evol 49:629-638

Klanten OS, Choat HJ, Van Herwerden L (2007) Extreme genetic diversity and temporal rather than spatial partitioning in a widely distributed coral reef fish. Mar Biol 150:659-670

Kuiter RH (1998) Photo guide to fishes of the Maldives. Atoll Editions, Yorkeys Knob

> Kuroki M, Aoyama J, Miller MJ, Wouthuyzen S, Arai T, Tsukamoto K (2006) Contrasting patterns of growth and migration of tropical anguillid leptocephali in the western Pacific and Indonesian Seas. Mar Ecol Prog Ser 309: 233-246

Leis JM, Miller JM (1976) Offshore distributional patterns of Hawaiian fish larvae. Mar Biol 36:359-367

> Lester SE, Ruttenberg BI (2005) The relationship between pelagic larval duration and range size in tropical reef fishes: a synthetic analysis. Proc Biol Sci 272:585-591

> McCleave JD, Miller JD (1994) Spawning of Conger oceanicus and Conger triporiceps (Congridae) in the Sargasso Sea and subsequent distribution of leptocephali. Environ Biol Fishes 39:339-355

Mehta RS (2009) Ecomorphology of the moray bite: relationship between dietary extremes and morphological diversity. Physiol Biochem Zool 82:90-103

Miller MJ (2009) Ecology of Anguilliform leptocephali: remarkable transparent fish larvae of the ocean surface layer. Aqua-BioSci Monogr 2:1-94

Miller MJ, McCleave JD (2007) Species assemblages of leptocephali in the southwestern Sargasso Sea. Mar Ecol Prog Ser 344:197-212

Miller MJ, Aoyama J, Mochioka N, Otake T and others (2006) Geographic variation in the assemblages of leptocephali in the western South Pacific. Deep-Sea Res I 53: 776-794

Moyer JT, Zaiser MJ (1982) Reproductive behavior of moray eels at Miyake-jima, Japan. Jpn J Ichthyol 24:466-468

Mundy BC (2005) Checklist of the fishes of the Hawaiian Archipelago. Bishop Mus Bull Zool 6:1-704

Myers RF (1991) Micronesian reef fishes, 2nd edn. Coral Graphics, Guam

Randall JE (2007) Reef and shore fishes of the Hawaiian
Islands. Sea Grant College Program, University of Hawaii, Honolulu, HI

Reece JS, Bowen BW, Joshi K, Goz V, Larson A (2010a) Phylogeography of two moray eels indicates high dispersal throughout the Indo-Pacific. J Hered 102:1-12

Reece JS, Bowen BW, Larson A (2010b) Molecular phylogenetics of moray eels (Murenidae) demonstrates multiple origins of a shell-crushing jaw (Gymnomuraena, Echidna) and multiple colonizations of the Atlantic Ocean. Mol Phylogenet Evol 57:829-835

Réveillac E, Feunteun E, Berrebi P, Gagnaire PA, LecomteFiniger R, Bosc P, Robinet T (2008) Anguilla marmorata larval migration plasticity as revealed by otolith microstructural analysis. Can J Fish Aquat Sci 65: 2127-2137

Rocha LA, Bass AL, Robertson DR, Bowen BW (2002) Adult habitat preferences, larval dispersal, and the comparative phylogeography of three Atlantic surgeonfishes (Teleostei: Acanthuridae). Mol Ecol 11:243-251

$>$ Rogers AR (1995) Genetic evidence for a Pleistocene population explosion. Evolution 49:608-615

> Rogers AR, Harpending H (1992) Population growth makes waves in the distribution of pairwise genetic differences. Mol Biol Evol 9:552-569

Rosenberg MS, Anderson C (2011) PASSaGE: pattern analysis, spatial statistics and geographic exegesis. Version 2. Methods Ecol Evol 2:229-232

Rozas J, Sánchez-DelBarrio C, Messeguer X, Rozas R (2003) DNAsp, DNA polymorphism analyses by the coalescent and other methods. Bioinformatics 19:2496-2497

Sampayo EM, Franceschinis L, Hoegh-Guldberg O, Dove S (2007) Niche partitioning of closely related symbiotic dinoflagellates. Mol Ecol 16:3721-3733

Scharf FS, Juanes F, Rountree RA (2000) Predator size-prey size relationships of marine fish predators: interspecific variation and effects of ontogeny and body size on trophic-niche breadth. Mar Ecol Prog Ser 208:229-248

Schneider S, Excoffier L (1999) Estimation of demographic parameters from the distribution of pairwise differences when the mutation rates vary among sites: application to human mitochondrial DNA. Genetics 152:1079-1089

Smith DG (1989) Family Muraenidae: Leptocephali. In: Böhlke EB (ed) Fishes of the Western North Atlantic. Sears Foundation for Marine Research, New Haven, CT, p 900-916

Sommer CW, Schneider W, Poutiers JM (1996) FAO species identification field guide for fishery purposes. The Living Marine Resources of Somalia. FAO, Rome

Thresher RE (1984) Reproduction in reef fishes. TFH Publications, Neptune City, NJ

Voris HK (2000) Maps of Pleistocene sea levels in Southeast Asia: shorelines, river systems and time durations. J Biogeogr 27:1153-1167

Waples RS (1987) A multispecies approach to the analysis of gene flow in marine shore fishes. Evolution 41:385-400

> Weersing K, Toonen RJ (2009) Population genetics, larval dispersal, and connectivity in marine systems. Mar Ecol Prog Ser 393:1-12

Yukihira H, Shibuno T, Hashimoto H, Gushima K (1994) Feeding habits of moray eels (Pisces: Muraenidae) at Kuchierabu-jima. J Fac Appl Biol Sci 33:159-166

Submitted: October 26, 2010; Accepted: June 9, 2011 Proofs received from author(s): September 8, 2011 